\title{
Video-Assisted Retroperitoneal Debridement (VARD) of Infected Necrotizing Pancreatitis: An Update
}

\author{
Sandra van Brunschot • Marc G. Besselink • \\ Olaf J. Bakker • Marja A. Boermeester · Hein G. Gooszen • \\ Karen D. Horvath $\cdot$ Hjalmar C. van Santvoort
}

Published online: 16 March 2013

(C) Springer Science + Business Media New York 2013

\begin{abstract}
The treatment of necrotizing pancreatitis has changed considerably over the last decades. Intervention is now primarily performed in case of infected necrosis, is preferably delayed to approximately 4 weeks after onset of disease and minimally invasive techniques have gained popularity. Percutaneous catheter drainage obviates the need for additional necrosectomy in around $30 \%$ of patients and should, therefore, be the first step of treatment. Minimally invasive necrosectomy can be performed as a next step in those patients who do not improve after drainage. This review discusses the background, technique, and results of the literature of a form of minimally invasive retroperitoneal necrosectomy: video-assisted retroperitoneal debridement.
\end{abstract}

Hjalmar C. van Santvoort for the Dutch Pancreatitis Study Group.

S. van Brunschot · H. G. Gooszen

Department of OR/Clinical Surgical Research, Radboud

University Nijmegen Medical Center, Nijmegen,

The Netherlands

M. G. Besselink - M. A. Boermeester

Department of Surgery, Academic Medical Center, Amsterdam,

The Netherlands

O. J. Bakker · H. C. van Santvoort ( $\square)$

Department of Surgery, University Medical Center Utrecht,

HP G04.228, PO Box 85500, 3508 GA Utrecht,

The Netherlands

e-mail: h.vansantvoort@pancreatitis.nl

K. D. Horvath

Department of Surgery, University of Washington, Seattle, WA, USA
Keywords Necrotizing pancreatitis - Infected necrosis · Minimally invasive $\cdot$ Intervention · Video-assisted retroperitoneal debridement (VARD) - Step-up approach

\section{Introduction}

Acute pancreatitis is a common and potentially life threatening disease. In the majority of patients the clinical course is mild and resolves spontaneously. Overall mortality is approximately $5 \%$ [1]. About $20 \%$ of patients with acute pancreatitis develop necrotizing pancreatitis with necrosis of the pancreatic parenchyma or extrapancreatic fatty tissue. Necrotizing pancreatitis is associated with a mortality of $15 \%$ [2]. The two major causes of mortality are multiple organ failure in the acute phase, and secondary bacterial infection of necrosis with subsequent sepsis and organ failure in the late phase. Infection of necrosis occurs in around $30 \%$ of patients with necrotizing pancreatitis, with a peak incidence after three to four weeks from disease onset. Infected necrosis considerably increases mortality to $12-39 \%[2-5,6 \bullet \bullet]$.

Currently, there is no convincing evidence that the routine use of antibiotic prophylaxis in (predicted) severe acute pancreatitis reduces the risk of infected necrosis and mortality [7-9]. Most international guidelines do not recommend routine antibiotic prophylaxis [1, 10].

Patients with sterile necrosis can usually be treated conservatively (i.e., without any form of radiologic, endoscopic or surgical intervention) $[1,10,11]$. An intervention for sterile extrapancreatic collections carries a serious risk of introducing infection, which increases mortality and necessitate additional interventions [12-15].

Infected necrosis on the other hand, is virtually always an indication for intervention (Fig. 1). Traditionally, primary open surgical necrosectomy was performed to 
completely remove the infected necrosis. Open surgery is very invasive and associated with a relatively high rate of complications (34-95\%) and mortality (11-39\%) [4, 5, 16-22]. In an effort to reduce complications and mortality in recent years, minimally invasive radiologic, endoscopic, and surgical techniques have been introduced. Minimally invasive techniques are thought to induce less physiological stress as compared with open surgical necrosectomy. Reduced surgical stress might decrease the risk of complications in these often already severely ill patients.

The timing of intervention for infected necrosis is also changing. Whereas necrosectomy was once performed very early after the onset of disease, intervention is now increasingly delayed to approximately three to four weeks after onset of disease resulting in lower complications and mortality rates [23-26]. In order to postpone intervention, patients with signs of infected necrosis are initially treated with broad-spectrum antibiotics and maximal support of organ systems. This allows for further encapsulation of collections, which theoretically improves the condition for intervention and thereby decreases the risk of complications. A recent large prospective study showed in multivariable analysis that patients with longer time between admission and intervention had significantly lower mortality [2].

\section{Video-Assisted Retroperitoneal Debridement}

\section{Background}

A frequently used minimally invasive surgical intervention for infected necrosis in the United States and The

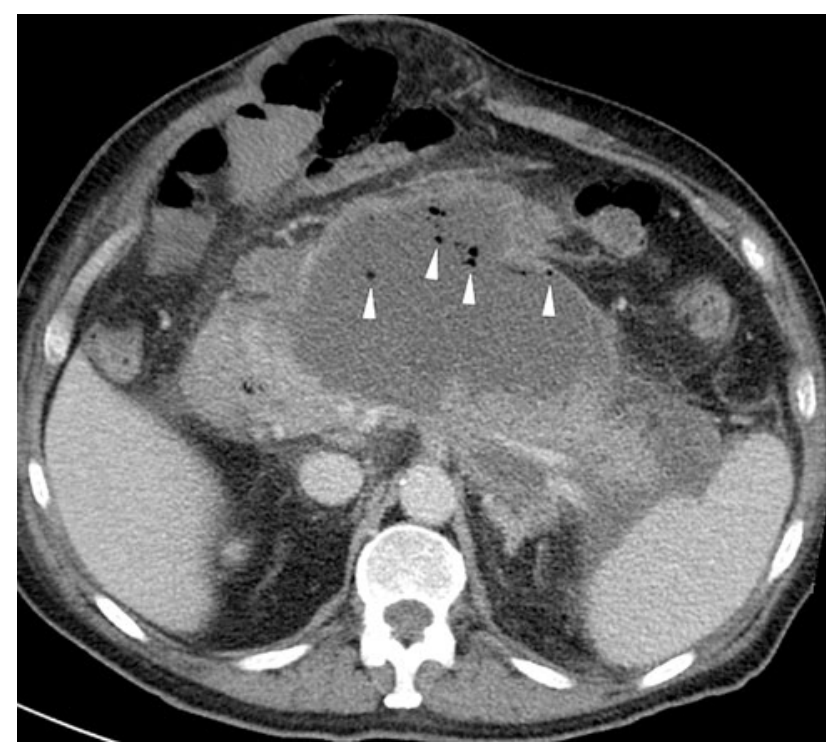

Fig. 1 Infected necrotizing pancreatitis. Heterogeneous collection in the pancreatic and extrapancreatic area with impacted gas bubbles (arrowheads), often a pathognomonic sign of infected necrosis
Netherlands is video-assisted retroperitoneal debridement (VARD). The VARD procedure aims at reducing complications and mortality by minimizing surgical stress in the already critically ill patient. Surgical stress is reduced by minimizing the surgical incision and staying solely retroperitoneal without contaminating the intraperitoneal space.

The VARD procedure was first described by Horvath et al. [27] in 2001. This first report described the results of six patients who underwent percutaneous drainage followed by VARD from 1995 to 1999 . Four patients were successfully treated and laparotomy with its related high complications was avoided. These results were followed by a case-matched study in The Netherlands comparing 15 patients undergoing VARD with 15 patients undergoing open necrosectomy in necrotizing pancreatitis [28]. In the VARD group there was less postoperative organ failure and a trend toward lower mortality supporting a potential benefit of the retroperitoneal approach over laparotomy. These results were confirmed in a prospective safety and efficacy study on 40 patients with infected necrosis [29•]. In all patients percutaneous drain placement was the first intervention, resulting in a mean of 141 days between admission and necrosectomy. Sixty percent of patients were successfully treated with VARD, complications occurred in $36 \%$ and mortality was $4 \%$. These outcomes were both lower compared to laparotomy.

\section{Step-Up Approach}

The VARD procedure is intentionally always part of a "step-up approach" consisting of percutaneous retroperitoneal catheter drainage (PCD) followed, if necessary, by VARD (Fig. 2). Catheter drainage (e.g., radiologic or endoscopic) is technically feasible to institute in more than $95 \%$ of patients, often via a left-sided retroperitoneal route [6••]. The rationale of PCD is to treat infected necrosis as an abscess and drain the infected fluid under pressure, without actually removing necrosis. Drainage of the infected fluid may temporize sepsis, improve the patient's clinical condition, and allow for further encapsulation or resorption of the necrotic collection. Hereby, necrosectomy may be postponed and even obviated in a considerable number of patients.

A systematic review on the role of PCD in (infected) necrotizing pancreatitis in which the data from 384 patients from 11 studies were pooled, showed that more than half of the patients were successfully treated with PCD alone and did not need to undergo additional necrosectomy [30•]. These results were confirmed by the randomized controlled multicenter PANTER trial wherein $35 \%$ of patients were successfully treated with percutaneous drainage only [6••]. In an additional prospective observational study, PCD was performed as first intervention in $63 \%$ of patients with 
(suspected) infected necrosis. In $35 \%$ of these patients there was no need for additional necrosectomy [2].

The preferred route for PCD is through the left retroperitoneum so that the drain can be used as a guide wire for VARD procedure (if necessary) and the peritoneal cavity is not contaminated.

\section{Preoperative Preparation}

The location and size of the collections with infected necrosis, and the accessibility is determined on a contrastenhanced CT (CECT). The relation of the collections to the left abdominal wall, Gerota's fascia, the colon and major blood vessels are landmarks to decide on feasibility of PCD through the left flank. Percutaneous drainage through the left retroperitoneum is feasible in more than $65 \%$ of patients with infected necrosis and an indication for intervention [31]. Typically, the retroperitoneal drain is placed over Gerota's fascia, just anterior to the left kidney (Fig. 3). A minimum drain size of 12-14 Fr should be pursued. However, upsizing to larger bore drains (18-22 Fr) may be associated with higher success rates. Broad spectrum antibiotics aimed at intestinal microorganisms are administered before intervention for a maximum duration of 14 days. After placement of the PCD, aspirate is sent for microbiological assessment and the PCD is flushed with $50 \mathrm{ml}$ saline, three times daily in order to keep the drain open and improve lavage of the collection.

The effect of PCD is awaited for at least $72 \mathrm{~h}$. If the patient does not improve after $72 \mathrm{~h}$ or deteriorates, a CECT is repeated to determine whether the drain is in good position and there are no additional collections. In case of additional or remnant collections the drain(s) can be

A
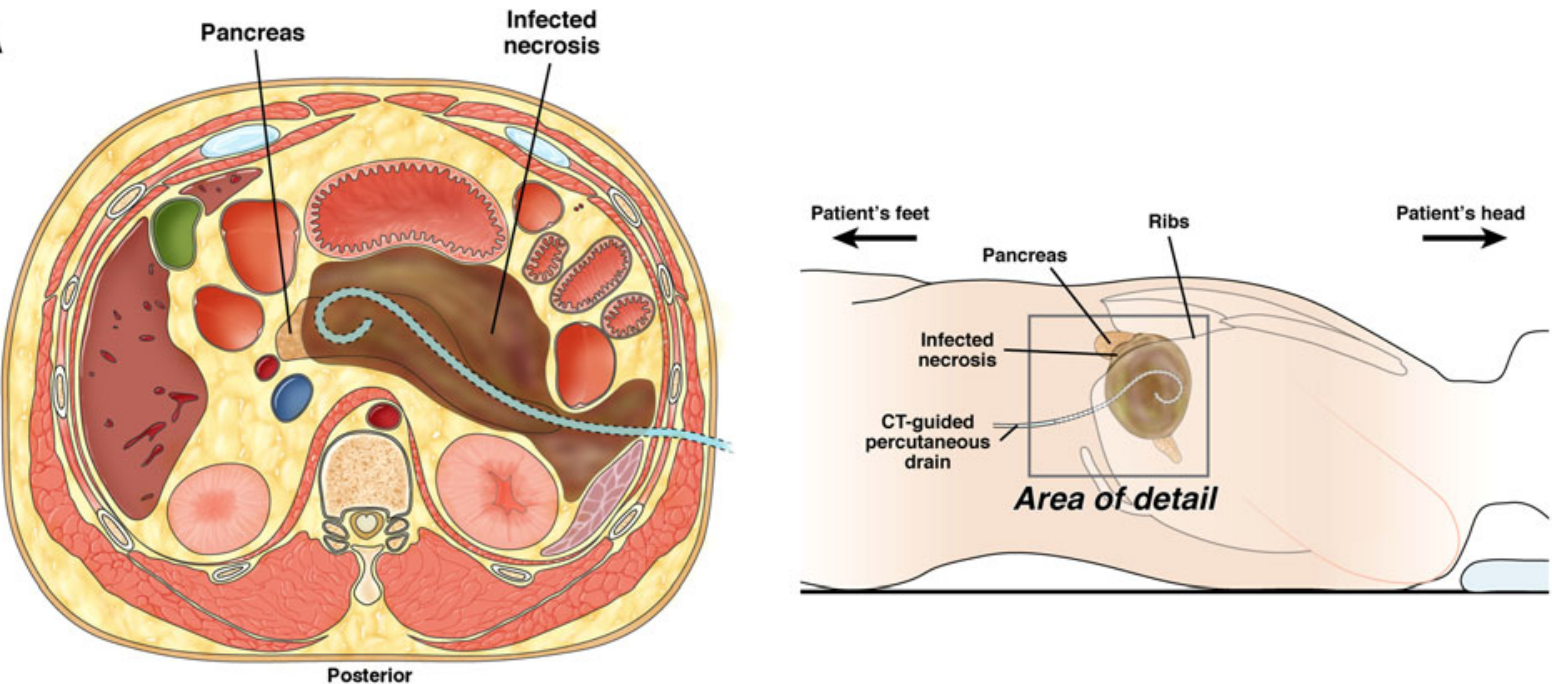

B

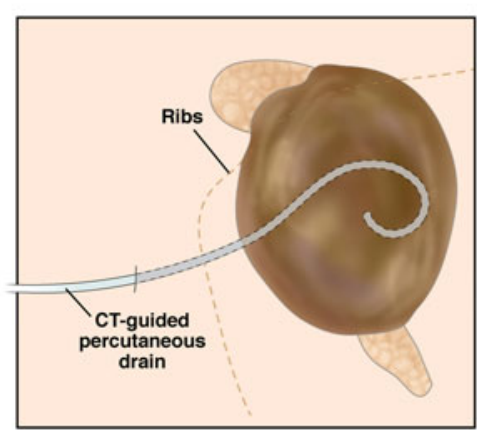

Fig. 2 Surgical step-up approach consisting of percutaneous catheter drainage (PCD) and video-assisted retroperitoneal debridement (VARD). a Cross-sectional image and torso depicting a extrapancreatic collection with fluid and necrosis. The preferred access route is through the left retroperitoneal space between the left kidney, dorsal spleen and descending colon. A percutaneous catheter drain is inserted in the collection to mitigate sepsis and postpone or even
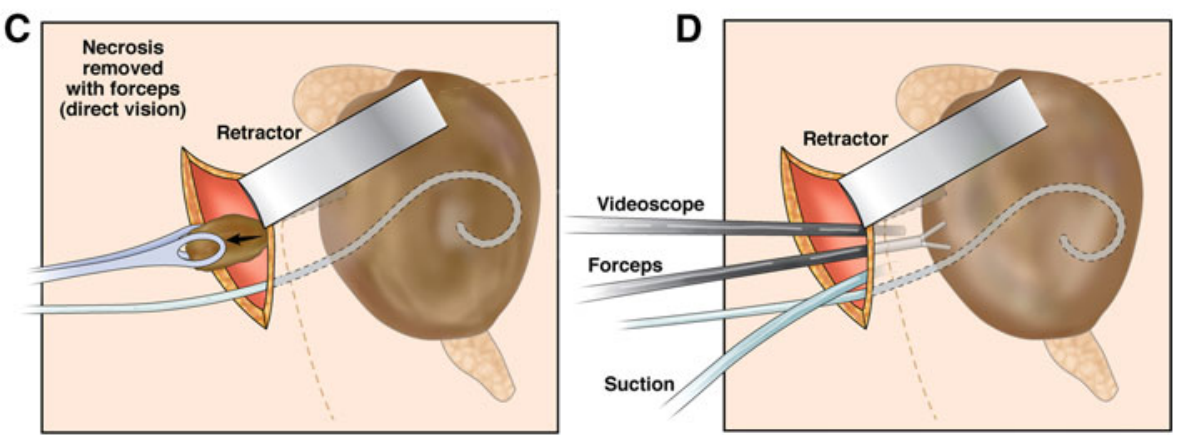

obviate necrosectomy. The area of detail is shown in b. c A $5 \mathrm{~cm}$ subcostal incision is made and the previously placed percutaneous drain is followed into the retroperitoneum to enter the necrotic collection. The first necrosis is removed under direct vision with a long grasping forceps. This is followed by further debridement under videoscopic assistance in d (Reprinted from van Brunschot et al. [45]; copyright 2012, with permission from Elsevier.) 

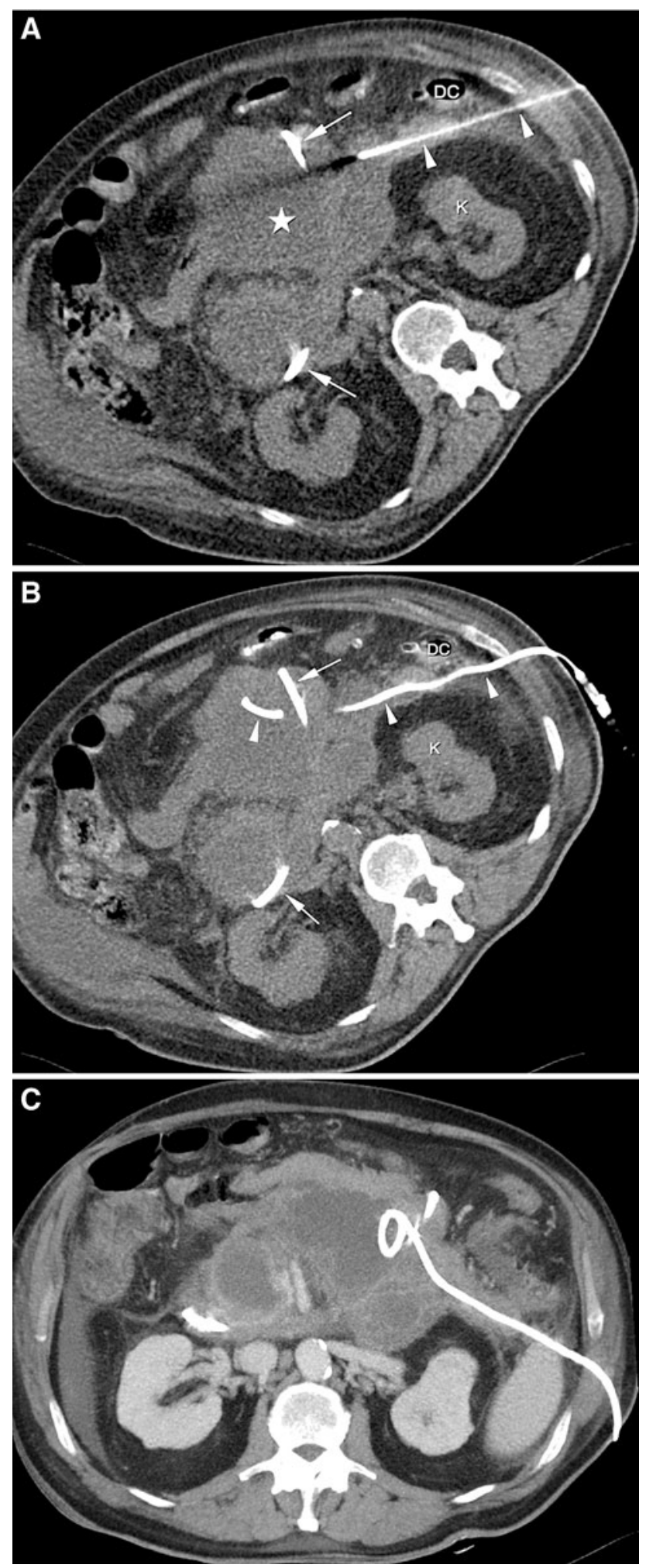

upgraded to the most optimal diameter of $18 \mathrm{Fr}$ or more and additional drains can be placed. If this extended percutaneous drainage is not rapidly successful, a VARD is performed.
4 Fig. 3 Percutaneous catheter drainage. Axial CT in right decubitus position for optimal retroperitoneal positioning of the percutaneous drain (arrows point at the nasojejunal feeding tube, the white star to the collection, $D C$ is the descending colon, and $K$ the left kidney). a CT guided needle (arrowheads) positioning through the left retroperitoneum. b Percutaneous retroperitoneal catheter (arrowheads) placement from the left flank. c Control CT showing the percutaneous catheter drain positioned in the extrapancreatic collection via the left flank (between the descending colon and spleen)

\section{Technique}

General anesthesia with endotracheal intubation is required. The patient is positioned in supine position and $30^{\circ}$ tilted towards the right side using an inflatable surgical positioning mattress or by a roll under the left flank. The left arm is positioned over the patients head. Before draping the patient, it is recommended to mark the following landmarks: xiphoid, costal margin, anterior superior iliac spine, mid-axillary line as well as the planned incision site. The $4-5 \mathrm{~cm}$ incision site is marked one or two fingers below the left costal margin over the mid axillary line, near the percutaneous routing drain. Next, the entire abdomen and flank are prepared and draped to enable conversion to laparotomy.

A left subcostal $4-5 \mathrm{~cm}$ incision is performed over the previously marked site and the muscles are divided sequentially (Fig. 2). Subsequently the drain is located with the palpating finger and followed into the collection with infected necrosis. Opening of the collection may be facilitated by using a clamp over the drain as the collection wall can be quite fibrotic. Once the collection is opened, pus will drain spontaneously. The very first necrosis is removed blindly using finger fracture, suction and an extended ring forceps (e.g., similar to that used for vascular graft tunneling in vascular surgery). Next, a zero degree laparoscope is introduced through the incision and the ring forceps is used parallel to the videoscope, in order to remove the necrosis under full videoscopic vision. Only loose necrosis is removed to minimize the risk of bleeding from viable pancreatic tissue and nearby blood vessels. In case of bleeding, a laparoscopic clip applier may be useful. If this is not feasible and the bleeding is of arterial origin, we advise packing the collection and transporting the patient to interventional radiology for coil embolization. In case of venous bleeding, packing should suffice to stop the bleeding, followed by repeat necrosectomy after $24-48 \mathrm{~h}$. In case of severe hemodynamic instability, not improving by packing, the procedure should be converted to laparotomy to obtain control over the bleeding.

It is not the goal of VARD to remove all necrosis. However, leaving large undrained pockets of necrosis should be avoided because this may cause ongoing sepsis. In general, the more complete the encapsulation, the easier the necrosectomy can be performed. A complex of cavities, 


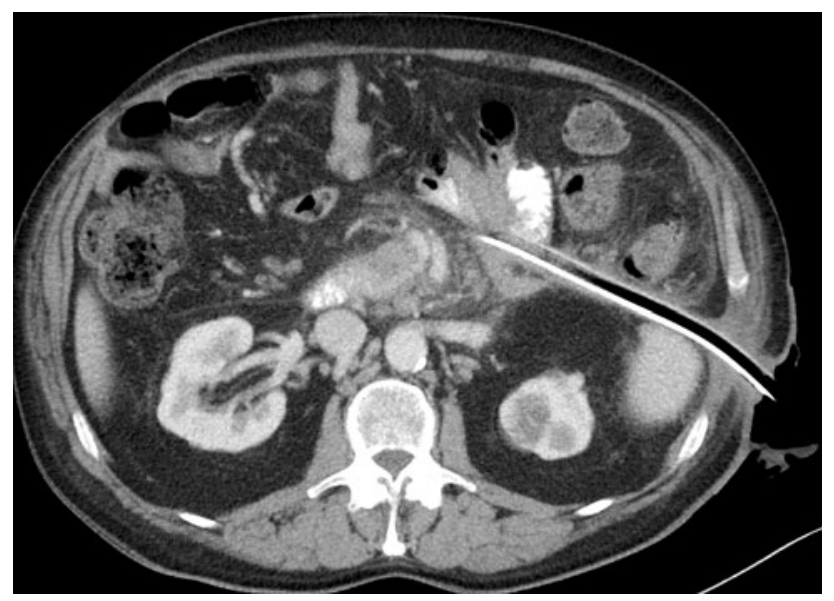

Fig. 4 Follow-up CT after video-assisted retroperitoneal debridement (VARD). Axial CT showing a large bore surgical drain via the left flank, placed at the end of a VARD procedure for continuous postoperative lavage

not approachable through one incision, is quite rare but sometimes requires another incision in the left groin and/or the right flank.

After completion of the procedure, two large bore surgical drains are placed into the collection, one deep in the collection and one more superficial (Fig. 4). The fascia must be closed over the drains. The skin can be closed or left open for healing by secondary intention.

\section{Postoperative Care}

Postoperatively, the drains are continuously lavaged with increasing amounts of saline, building up to 101 per $24 \mathrm{~h}$ in the first 3 days. Broad spectrum antibiotics are continued and then narrowed based on culture and sensitivity data from material collected during drainage and/or surgical procedures. If cultures remain negative, antibiotic treatment is stopped. We advise stepwise retraction of the drains once the cavity has collapsed as shown on sonogram or CECT.

Results from the Literature

\section{Studies and Quality}

Since 1998 nine studies have been published describing a minimally invasive retroperitoneal surgical approach [4, 6•• 19, 28, 29•, 32••, 33, 34, 35]. Different terms are used to describe more or less the same intervention, varying from endoscopic retroperitoneal drainage, translumbar retroperitoneal approach, minimally invasive pancreatic necrosectomy (MIPN), minimal access retroperitoneal pancreatic necrosectomy (MARPN), to VARD. Of these techniques, MIPN and MARPN are purely percutaneous techniques. For both MIPN and MARPN, a guide wire is placed via a left percutaneous retroperitoneal approach. This tract is dilated to $30 \mathrm{Fr}$ using serial renal dilators, and the necrotic material is removed under direct vision using an operating nephroscope and continuous irrigation. Since this technique differs from VARD, the two studies describing MIPN and MARPN were excluded $[4,19]$. The remaining seven studies including 128 patients were

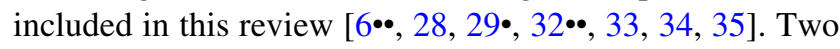
studies were randomized controlled trials $[6 \bullet \bullet, 32 \bullet \cdot]$ and sample sizes are ranging from 6 to 32 patients. Study characteristics are summarized in Table 1.

All data are presented as mean and weighted means using the method described by Hozo et al. [36] to calculate the mean using the median, low and high end of the range and sample size. In order to be able to report data on the subgroup VARD in two studies, we received additional information through personal communication with the author $[6 \bullet \cdot, 32 \bullet \cdot]$.

The methodological quality of the selected studies was determined using the validated Downs et al., and MINORS

Table 1 Characteristics of the included studies

\begin{tabular}{llllccc}
\hline Study & Country & Years & Study design & $\begin{array}{l}\text { Number of } \\
\text { patients }\end{array}$ & $\begin{array}{l}\text { Study period } \\
\text { (years) }\end{array}$ & $\begin{array}{l}\text { Follow-up } \\
\text { (months) }\end{array}$ \\
\hline Gambiez et al. [34] & France & 1998 & Retrospective cohort & 20 & $1990-1995(5)$ & 1 \\
Horvath et al. [35] & USA & 2001 & Retrospective cohort & 6 & $1995-1999(4)$ & 1 \\
Van Santvoort et al. [28] & The Netherlands & 2007 & Case-matched study & 15 & $1995-2005(10)$ & $\mathrm{nr}$ \\
Van Santvoort et al. [6••] & The Netherlands & 2010 & Randomised Controlled Trial & $24^{\text {a }}$ & $2005-2008(3)$ & 6 \\
Horvath et al. [29•] & USA & 2010 & Prospective cohort & $25^{\text {a }}$ & $2003-2007(4)$ & 6 \\
Castellanos et al. [33] & Spain & 2012 & Prospective cohort & 32 & $2000-2010(10)$ & 105 \\
Bakker et al. [32••] & The Netherlands & 2012 & Randomised Controlled Trial & $6^{\text {a }}$ & $2008-2010$ & 6 \\
\hline
\end{tabular}

$n r$ not reported

a Subgroup of patients from the original article who underwent VARD procedure 
Table 2 Methodological quality of the included studies

\begin{tabular}{|c|c|c|c|c|c|}
\hline Study & Inclusion criteria & Technique used & $\begin{array}{l}\text { MINORS } \\
\text { checklist [38] }\end{array}$ & $\begin{array}{l}\text { Checklist for (non-) } \\
\text { randomised trials [37] }\end{array}$ & $\begin{array}{l}\text { Mean MINORS and } \\
\text { Downs checklist }\end{array}$ \\
\hline Gambiez et al. [34] & $\begin{array}{l}\text { Necrotizing } \\
\text { pancreatitis }\end{array}$ & $\begin{array}{l}\text { Endoscopic } \\
\text { retroperitoneal } \\
\text { drainage }\end{array}$ & 5 & 6,3 & 5,7 \\
\hline Horvath et al. [35] & $\begin{array}{l}\text { Infected } \\
\text { pancreatic } \\
\text { necrosis }\end{array}$ & VARD & 5 & 5,2 & 5,1 \\
\hline $\begin{array}{l}\text { Van Santvoort } \\
\text { et al. [28] }\end{array}$ & $\begin{array}{l}\text { Infected } \\
\text { pancreatic } \\
\text { necrosis }\end{array}$ & VARD & 6,3 & 7,8 & 7,1 \\
\hline $\begin{array}{l}\text { Van Santvoort } \\
\text { et al. }\left[6^{\bullet \bullet}\right]\end{array}$ & $\begin{array}{l}\text { Infected } \\
\text { pancreatic } \\
\text { necrosis }\end{array}$ & VARD & 9,2 & 9,6 & 9,4 \\
\hline Horvath et al. [29•] & $\begin{array}{l}\text { Infected } \\
\text { pancreatic } \\
\text { necrosis }\end{array}$ & VARD & 8,8 & 8,9 & 8,9 \\
\hline $\begin{array}{l}\text { Castellanos } \\
\text { et al. [33] }\end{array}$ & $\begin{array}{l}\text { Infected } \\
\text { pancreatic } \\
\text { necrosis }\end{array}$ & $\begin{array}{l}\text { Translumbar } \\
\text { retroperitoneal } \\
\text { approach }\end{array}$ & 7,5 & 6,3 & 6,9 \\
\hline Bakker et al. [32••] & $\begin{array}{l}\text { Infected } \\
\text { pancreatic } \\
\text { necrosis }\end{array}$ & VARD & 9,2 & 9,6 & 9,4 \\
\hline
\end{tabular}

All scores are converted to a $0-10$ scale, with 10 reflecting the highest methodological score

checklist $[37,38]$. The mean of both scores was calculated in order to determine a final score. High methodological quality is defined as a score $\geq 8$, moderate quality as a score of 6-8, moderate/low quality as a score of 4-6 and low quality as a score $\leq 3$. The overall methodological quality of the selected studies was moderate with a mean score of 7,6 (Table 2). Three studies scored high on methodological quality.

Patient characteristics of selected studies are displayed in Table 3. Sixty-six percent of patients were male, the mean age was 54 years, follow-up 33 months, and with $54 \%$ biliary etiology was most common. Most studies reported predictive severity scores before intervention. Mean preoperative APACHE 11 score was 14, CT Severity Index (CTSI) 8, organ failure was present in $40 \%$ of patients and $60 \%$ of patients were admitted to the ICU. On average, intervention was postponed to 70 days after admission and $91 \%$ of patients had proven infected necrosis at first intervention.

\section{Clinical Outcome}

Outcome of VARD is shown in Table 4. Overall mortality was $13 \%$ (17 of 128 patients) with a range of $0-33 \%$ per study. Complications occurred in $35 \%$ of patients (29 of 82 patients). Pancreatic fistulae and bleeding requiring intervention were the most common complications with $17 \%$ (27 of 128 patients) and $13 \%$ (16 of 128 patients), respectively. Other complications reported were enteric fistula in $9 \%$ (12 of 128 patients), perforation of a hollow organ in $4 \%$ ( 5 of 128 patients), and incisional hernia in $3 \%$ (4 of 128 patients).

On average 3 (range 1-5) VARD procedures were needed per patient. The mean number of VARD procedures needed in the three studies with high methodological

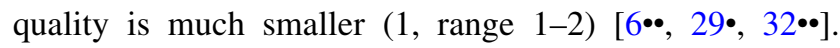
Successful treatment with VARD alone was achieved in $61 \%$ (49 of 81 ) of patients. Total mean hospital stay was 78 days.

\section{Endoscopic Transluminal Necrosectomy}

In order to further reduce complications and mortality, minimally invasive alternatives like endoscopic transluminal necrosectomy (ETN) are emerging. ETN is performed under conscious sedation without the need for general anesthesia [39]. Furthermore, no abdominal wall incisions are needed which potentially reduces the risk of procedure related complications such as new onset organ failure, fistula, and incisional hernia. ETN can also be performed as a step-up approach consisting of endoscopic transluminal drainage as a first step followed, if necessary, by ETN. 


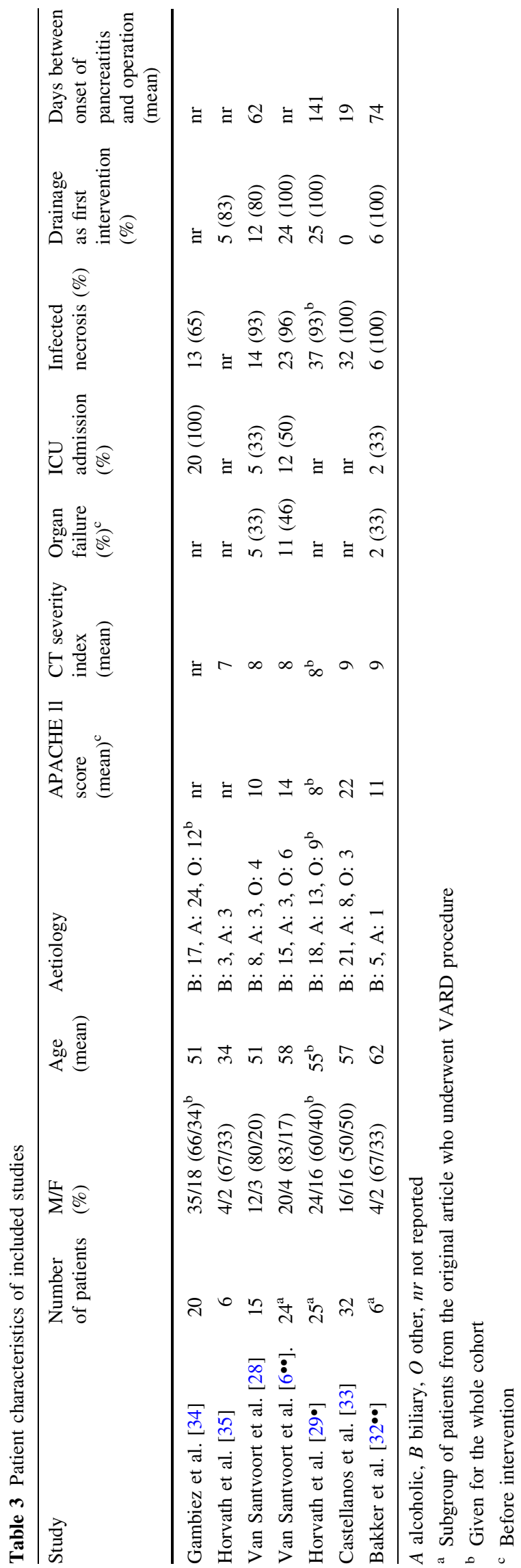

Several observational studies have been published on ETN [4, 40-42]. Results of reported studies are promising with a complication and mortality rate of 37 and $6 \%$, respectively. However, most of the studies were retrospective and mean methodological quality was moderate to low. Furthermore, the percentage of patients with proven infected necrosis and organ failure before intervention was low indicating probable selection bias.

The only randomized controlled trial comparing ETN with VARD was recently published [32••]. Twenty patients were randomized between ETN and VARD. One-third of the patients had organ failure before intervention and $95 \%$ of the patients had proven infected necrosis. ETN significantly reduced the proinflammatory response as measured by interleukine- 6 levels, as well as the composite clinical endpoint consisting of complications and mortality compared with VARD in patients with infected necrosis.

ETN seems a safe and successful alternative treatment. However, larger randomized controlled trails are needed to confirm these favorable results. In The Netherlands, a nationwide multicenter randomised trial comparing an endoscopic step-up approach with a surgical step-up approach (TENSION trial, controlled trials ISRCTN09186711) has recently started.

\section{Conclusions}

In recent years, the management of necrotizing pancreatitis underwent several changes. There has been a shift to perform intervention solely in case of infected necrosis and preferably only after a period of three to four weeks after onset of disease. Currently, the standard strategy for intervention is a step-up approach consisting of catheter drainage as a first step followed, if necessary, by necrosectomy which is often performed through a minimally invasive approach such as VARD or ETN [43•]. Percutaneous catheter drainage is possible in most patients and obviates the need for additional necrosectomy in $35 \%$ of patients. There are no randomized studies that have investigated which surgical technique for necrosectomy is superior in patients in whom percutaneous drainage has failed. The published observational cohort studies demonstrate that VARD is associated with a complication and mortality rate of 35 and $13 \%$, respectively. This is lower as compared to historical cohorts of open necrosectomy which report a complication and mortality rate of 34-95\% and 11-39\%, respectively. Retrospective comparative studies have confirmed that minimally invasive necrosectomy leads to less complications and lower mortality $[4,28,44]$.

In conclusion, VARD is a safe and effective minimally invasive technique for necrosectomy in patients with infected necrotizing pancreatitis. 


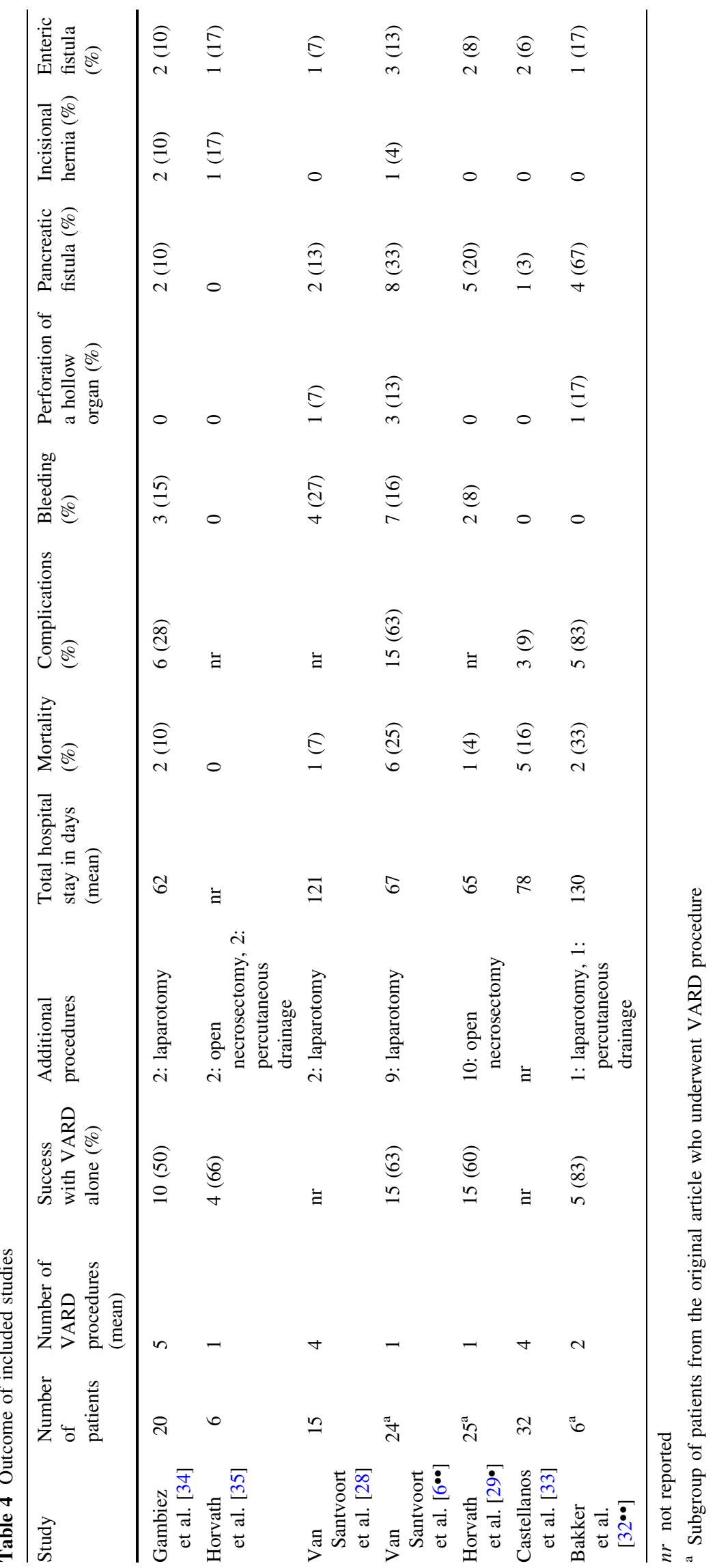


Acknowledgment Marja A. Boermeester has received Grant support from Abbott Laboratories, Baxter, LifeCell, and Ipsen.

Disclosure Sandra van Brunschot, Marc G. Besselink, Olaf J. Bakker, Hein G. Gooszen, Karen D. Horvath, Hjalmar C. van Santvoort declares that they have no conflict of interest.

\section{References}

Papers of particular interest, published recently, have been highlighted as:

- Of importance

- Of major importance

1. Banks PA, Freeman ML. Practice guidelines in acute pancreatitis. Am J Gastroenterol. 2006;101:2379-400.

2. van Santvoort HC, Bakker OJ, Bollen TL, Besselink MG, Ahmed Ali U, Schrijver AM, et al. A conservative and minimally invasive approach to necrotizing pancreatitis improves outcome. Gastroenterology. 2011;141:1254-63.

3. Besselink MG, van Santvoort HC, Buskens E, Boermeester MA, van Goor H, Timmerman HM, et al. Probiotic prophylaxis in predicted severe acute pancreatitis: a randomised, double-blind, placebo-controlled trial. Lancet. 2008;371:651-9.

4. Raraty MG, Halloran CM, Dodd S, Ghaneh P, Connor S, Evans J, et al. Minimal access retroperitoneal pancreatic necrosectomy: improvement in morbidity and mortality with a less invasive approach. Ann Surg. 2010;251:787-93.

5. Rodriguez JR, Razo AO, Targarona J, Thayer SP, Rattner DW, Warshaw AL, et al. Debridement and closed packing for sterile or infected necrotizing pancreatitis: insights into indications and outcomes in 167 patients. Ann Surg. 2008;247:294-9.

6. - van Santvoort HC, Besselink MG, Bakker OJ, Hofker HS, Boermeester MA, Dejong CH, et al. A step-up approach or open necrosectomy for necrotizing pancreatitis. $N$ Engl $J$ Med 2010;362:1491-502. This randomized controlled trial showed that the surgical step-up approach is superior to primary open necrosectomy and $35 \%$ of patients can be treated with solely percutaneous drainage.

7. de Vries AC, Besselink MG, Buskens E, Ridwan BU, Schipper M, van Erpecum KJ, et al. Randomized controlled trials of antibiotic prophylaxis in severe acute pancreatitis: relationship between methodological quality and outcome. Pancreatology. 2007:7:531-8.

8. Villatoro E, Mulla M, Larvin M. Antibiotic therapy for prophylaxis against infection of pancreatic necrosis in acute pancreatitis. Cochrane Database Syst Rev 2010; 4: CD002941.

9. Wittau M, Mayer B, Scheele J, Henne-Bruns D, Dellinger EP, Isenmann R. Systematic review and meta-analysis of antibiotic prophylaxis in severe acute pancreatitis. Scand J Gastroenterol. 2011;46:261-70.

10. AGA. Institute medical position statement on acute pancreatitis. Gastroenterology. 2007;132:2019-21.

11. Nathens AB, Curtis JR, Beale RJ, Cook DJ, Moreno RP, Romand $\mathrm{JA}$, et al. Management of the critically ill patient with severe acute pancreatitis. Crit Care Med. 2004;32:2524-36.

12. Besselink MG, van Santvoort HC, Bakker OJ, Bollen TL, Gooszen HG. Draining sterile fluid collections in acute pancreatitis? Primum non nocere! Surg Endosc. 2011;25:331-2.

13. van Santvoort HC, Besselink MG, Bakker OJ, Vleggaar FP, Timmer R, Weusten BL, et al. Endoscopic necrosectomy in necrotising pancreatitis: indication is the key. Gut. 2010;59:1587.
14. Walser EM, Nealon WH, Marroquin S, Raza S, Hernandez JA, Vasek J. Sterile fluid collections in acute pancreatitis: catheter drainage versus simple aspiration. Cardiovasc Interv Radiol. 2006;29:102-7.

15. Zerem E, Imamovic G, Omerovic S, Imsirovic B. Randomized controlled trial on sterile fluid collections management in acute pancreatitis: should they be removed? Surg Endosc. 2009;23: 2770-7.

16. Ashley SW, Perez A, Pierce EA, Brooks DC, Moore FD Jr, Whang EE, et al. Necrotizing pancreatitis: contemporary analysis of 99 consecutive cases. Ann Surg. 2001;234:572-9. discussion 9-80.

17. Babu BI, Sheen AJ, Lee SH, O'Shea S, Eddleston JM, Siriwardena AK. Open pancreatic necrosectomy in the multidisciplinary management of postinflammatory necrosis. Ann Surg. 2010;251: 783-6.

18. Buchler MW, Gloor B, Muller CA, Friess H, Seiler CA, Uhl W. Acute necrotizing pancreatitis: treatment strategy according to the status of infection. Ann Surg. 2000;232:619-26.

19. Connor S, Alexakis N, Raraty MG, Ghaneh P, Evans J, Hughes $\mathrm{M}$, et al. Early and late complications after pancreatic necrosectomy. Surgery. 2005;137:499-505.

20. Howard TJ, Patel JB, Zyromski N, Sandrasegaran K, Yu J, Nakeeb A, et al. Declining morbidity and mortality rates in the surgical management of pancreatic necrosis. J Gastrointest Surg. 2007;11:43-9.

21. Rau B, Bothe A, Beger HG. Surgical treatment of necrotizing pancreatitis by necrosectomy and closed lavage: changing patient characteristics and outcome in a 19-year, single-center series. Surgery. 2005;138:28-39.

22. Tsiotos GG, Luque-de Leon E, Sarr MG. Long-term outcome of necrotizing pancreatitis treated by necrosectomy. Br J Surg. 1998;85:1650-3.

23. Besselink MG, Verwer TJ, Schoenmaeckers EJ, Buskens E, Ridwan BU, Visser MR, et al. Timing of surgical intervention in necrotizing pancreatitis. Arch Surg. 2007;142:1194-201.

24. Fernandez-del Castillo C, Rattner DW, Makary MA, Mostafavi A, McGrath D, Warshaw AL. Debridement and closed packing for the treatment of necrotizing pancreatitis. Ann Surg. 1998;228: 676-84.

25. Mier J, Leon EL, Castillo A, Robledo F, Blanco R. Early versus late necrosectomy in severe necrotizing pancreatitis. Am J Surg. 1997;173:71-5.

26. Uhl W, Warshaw A, Imrie C, Bassi C, McKay CJ, Lankisch PG, et al. IAP guidelines for the surgical management of acute pancreatitis. Pancreatology. 2002;2:565-73.

27. Horvath KD, Kao LS, Wherry KL, Pellegrini CA, Sinanan MN. A technique for laparoscopic-assisted percutaneous drainage of infected pancreatic necrosis and pancreatic abscess. Surg Endosc. 2001;15:1221-5

28. van Santvoort HC, Besselink MG, Bollen TL, Buskens E, van Ramshorst B, Gooszen HG. Case-matched comparison of the retroperitoneal approach with laparotomy for necrotizing pancreatitis. World J Surg. 2007;31:1635-42.

29. - Horvath K, Freeny P, Escallon J, Heagerty P, Comstock B, Glickerman DJ, et al. Safety and efficacy of video-assisted retroperitoneal debridement for infected pancreatic collections: a multicenter, prospective, single-arm phase 2 study. Arch Surg 2010;145:817-25. Prospective cohort study of high methodological quality reporting the safety and efficacy of VARD.

30. - van Baal MC, van Santvoort HC, Bollen TL, Bakker OJ, Besselink MG, Gooszen HG. Systematic review of percutaneous catheter drainage as primary treatment for necrotizing pancreatitis. Br J Surg 2011;98:18-27. This systematic review showed that in more than $55 \%$ of patients no additional necrosectomy was needed after percutaneous drainage. 
31. Besselink MG, van Santvoort HC, Schaapherder AF, van Ramshorst B, van Goor H, Gooszen HG, et al. Feasibility of minimally invasive approaches in patients with infected necrotizing pancreatitis. Br J Surg. 2007;94:604-8.

32. • Bakker OJ, van Santvoort HC, van Brunschot S, Geskus RB, Besselink MG, Bollen TL, et al. Endoscopic transgastric vs surgical necrosectomy for infected necrotizing pancreatitis: a randomized trial. JAMA 2012;307:1053-61. This is the first randomized controlled trial comparing endoscopic transgastric necrosectomy wih surgical necrosectomy in infected necrotizing pancreatitis.

33. Castellanos G, Pinero A, Doig LA, Serrano A, Fuster M, Bixquert V. Management of infected pancreatic necrosis using retroperitoneal necrosectomy with flexible endoscope: 10 years of experience. Surg Endosc 2012;27(2):443-53.

34. Gambiez LP, Denimal FA, Porte HL, Saudemont A, Chambon JP, Quandalle PA. Retroperitoneal approach and endoscopic management of peripancreatic necrosis collections. Arch Surg. 1998;133:66-72.

35. Horvath KD, Kao LS, Ali A, Wherry KL, Pellegrini CA, Sinanan MN. Laparoscopic assisted percutaneous drainage of infected pancreatic necrosis. Surg Endosc. 2001;15:677-82.

36. Hozo SP, Djulbegovic B, Hozo I. Estimating the mean and variance from the median, range, and the size of a sample. BMC Med Res Methodol. 2005;5:13.

37. Downs SH, Black N. The feasibility of creating a checklist for the assessment of the methodological quality both of randomised and non-randomised studies of health care interventions. J Epidemiol Community Health. 1998;52:377-84.

38. Slim K, Nini E, Forestier D, Kwiatkowski F, Panis Y, Chipponi J. Methodological index for non-randomized studies (minors): development and validation of a new instrument. ANZ J Surg. 2003;73:712-6.

39. Baron TH, Harewood GC, Morgan DE, Yates MR. Outcome differences after endoscopic drainage of pancreatic necrosis, acute pancreatic pseudocysts, and chronic pancreatic pseudocysts. Gastrointest Endosc. 2002;56:7-17.

40. Gardner TB, Coelho-Prabhu N, Gordon SR, Gelrud A, Maple JT, Papachristou GI, et al. Direct endoscopic necrosectomy for the treatment of walled-off pancreatic necrosis: results from a multicenter U.S. series. Gastrointest Endosc. 2011;73:718-26.

41. Papachristou GI, Takahashi N, Chahal P, Sarr MG, Baron TH. Peroral endoscopic drainage/debridement of walled-off pancreatic necrosis. Ann Surg. 2007;245:943-51.

42. Seifert H, Biermer M, Schmitt W, Jurgensen C, Will U, Gerlach $\mathrm{R}$, et al. Transluminal endoscopic necrosectomy after acute pancreatitis: a multicentre study with long-term follow-up (the GEPARD Study). Gut. 2009;58:1260-6.

43. - Freeman MLW, J.; van Santvoort, H.C. Interventions for necrotizing pancreatitis. Summary of a multidisciplinary consensus conference. Pancreas 2012;41(8):1176-1194. Consensus guideline of interventions for necrotizing pancreatitis.

44. Bausch D, Wellner U, Kahl S, Kuesters S, Richter-Schrag HJ, Utzolino S, et al. Minimally invasive operations for acute necrotizing pancreatitis: comparison of minimally invasive retroperitoneal necrosectomy with endoscopic transgastric necrosectomy. Surgery. 2012;152:S128-34.

45. van Brunschot $\mathrm{S}$, Bakker OJ, Besselink MG, et al. Treatment of necrotizing pancreatitis. Clin Gastroenterol Hepatol. 2012;10(11): 1190-201. 